Archives of Agriculture and Environmental Science

\title{
Adoption of disaster risk reduction strategy in agriculture sector at Southkhali Union of Sharankhola Upazila, Bangladesh
}

\author{
Prome Debnath $^{1^{*}}$ (D) , Md. Mainul Hasan ${ }^{2}$, A.K.M. Abdul Ahad Biswas ${ }^{1}$ and Avijit Biswas ${ }^{3}$ \\ ${ }^{1}$ Department of Disaster Risk Management, Patuakhali Science and Technology University, Patuakhali, BANGLADESH \\ ${ }^{2}$ Department of Agricultural Botany, Patuakhali Science and Technology University, Patuakhali, BANGLADESH \\ ${ }^{3}$ Department of Agriculture, Bangabandhu Sheikh Mujibur Rahman Science and Technology University, Gopalganj, BANGLADESH \\ "Corresponding author's E-mail: hritekaprome56@gmail.com
}

\section{ARTICLE HISTORY}

Received: 26 March 2019

Revised received: 12 May 2019

Accepted: 23 May 2019

\section{Keywords}

Adaptation strategy

Agriculture

Climate change

Disaster risk reduction

\begin{abstract}
Climate change is contemporary global threat especially for coastal area of Bangladesh which drastically affects in agricultural sector. The purpose of the study was to determine the extent of adopting disaster risk reduction strategies by farmer towards agriculture sector in Southkhali union of Sharankhola upazila. Data were collected following a structured pretested interview schedule, FGD and KII and then verified with secondary sources of information. Coefficients of Correlation and regression analysis were used to find out the contribution of factors to the variation of adopting disaster risk reduction strategy by farmers in agriculture sector. The study found that the salinity was the major climate change effect in agriculture sector of this area that resulted soil salinity in agriculture and the most common adopted strategies are rain water harvesting (90\%), tree plantation $(89.16 \%)$ and homestead gardening (80.83\%) in agriculture. Correlation analysis indicated that age $\left(0.383^{* *}\right)$, farming experience $\left(0.441^{* *}\right)$, communication exposure $\left(0.271^{*}\right)$ and organizational support $\left(0.226^{*}\right)$ had positive significant relationship and climate change effect $\left(-0.266^{* *}\right)$ had negative significant relationship with adoption of disaster risk reduction strategy of farmers in agriculture. Regression analysis revealed that farming experience $(\beta=0.546)$ has the strongest contribution and climate change effect $(\beta=-0.139)$ had negative contribution to the adoption of disaster risk reduction strategies in agriculture. Based on this observation it can be concluded that the awareness and skill of farmer should be more developed through arranging different training program and providing necessary support to promote environmentally safe cultivation and to enhance climate change adaptation in agriculture sector.
\end{abstract}

(C)2019 Agriculture and Environmental Science Academy

Citation of this article: Debnath, P., Hasan, M.M., Biswas, A.K.M.A.A. and Biswas, A. (2019). Adoption of disaster risk reduction strategy in agriculture sector at Southkhali Union of Sharankhola Upazila, Bangladesh. Archives of Agriculture and Environmental Science, 4(2): 141-150, https://dx.doi.org/10.26832/24566632.2019.040203

\section{INTRODUCTION}

Bangladesh is an agriculture based country and this sector provide a huge support to enhance its economic growth. But day to day climate change has become devastating and fall impact on the life and livelihoods of the people especially who lives in coastal, arid and semi-arid regions of Bangladesh (MoP, 2011). Agriculture contributed 14.10 percent to the Gross Domestic Product (GDP) in 2017-18; approximately 9.28 percent of the GDP was derived from crops (BBS, 2011; 2018). But its geo- physical location, poor socioeconomic development, weak institutional arrangement and limited local capacity (ADPC, 2008), may expected to result in declines in rice production 7.4\% every year over the period 2005-2050 (Yusuf et al., 2010) and accumulative total of 80 million tons over 2005-50 (GoB, 2008). Climate change has probability to decrease agricultural GDP by 3.1 percent per year-accumulative $\$ 36$ billion in lost value-added during 2005-50 (WB, 2013). Bangladesh in a regular basis experiencing different types of natural disasters due to climate change impacts, these are: floods / flash floods 
(almost $80 \%$ of the total area of the country is prone to flooding), cyclones and storm surges (especially south and southeastern Parts of the country), salinity intrusion (especially the whole coastal belt) and extreme temperature and drought (especially north and north-western regions of the country) (Sikder and Xiaoying, 2014). Flooding, heavy rainfall, water logging and salinity intrusion etc. are the major climate change impacts which has potentiality to decline crop yields in southern coastal part of Bangladesh (Yusuf et al., 2010). It has already affected crop production and the area of arable land has decreased to a great extent. In Bangladesh among all crops, rice plays the leading role by providing $95 \%$ of total food production (GoB, 2008). Coastal area of Bangladesh has already been experiencing erosion; besides more the salinity intrusion and water logging are creating serious implications for the coastal land that was traditionally used for rice production (Tasnim, 2012). Last 100 years the sea level rise of $0.5 \mathrm{~m}$ had eroded approximately $162 \mathrm{~km}^{2}$ of Kutubdia, $147 \mathrm{~km}^{2}$ of Bhola and 117 $\mathrm{km}^{2}$ of Sandwip (CCC, 2007) and if this trend is continuing then sea water may intrude much longer distance in low-laying areas of Bangladesh (Karim and Mimura, 2008). The dominant land use in coastal Bangladesh is also agriculture and 144,085 and 83,416 hector gross and net-cropped areas are exist in the coastal zone of Bangladesh (Islam, 2004), but net-cropped area of coastal zone has been showing a decreasing trend over the years due to a combined impact of climate change. It has changed the agricultural cultivation patterns and people have to invest more to get optimum production. Consequently, they get less benefit despite of investing more capital, time and efforts. Along with the rural poverty incident is exacerbating due to adverse impacts on the agricultural sector (Kamruzzaman, 2015). Despite of these serious climate-related difficulties, Bangladesh may be able to adopt some adaptive responses that could mitigate these effects. Adopting of adaptation measures means to synthesize with natural or human systems to response in an actual or expected climatic conditions or risks (Kurukulasuriya and Mendelsohn, 2008). Exploratory standard recognizes that adaptation to climate change can potentially reduce its adverse effects, protect the livelihoods of poor farmers and reinforce any potential advantages it may bring (Gandure et al., 2013; Wheeler et al., 2013). So, the importance of disaster risk reduction (DRR) and integration of DRR with climate change has been crucial to reduce the disaster risks and effective adaptation to climate change to cope with the additional risks of different climatic disasters (Alauddin and Rahman, 2013). Adaptive responses can be two types, likeautonomous or planned (Shaw et al., 2013 and Park et al., 2012). According to farm level analysis it has recommended that when adaptation measures are implemented successfully then there has a large reduction of adverse impact from climate change on agricultural sector (Mendelsohn and Dinar, 1999). But there is a growing consensus that neither sound technological protocols, nor local techniques are enough to enhance farmers' capacity to overcome climate related risks and challenges. The integration of sound technological solutions with local practices is increas- ingly identified as a more-necessary pathway for sustainable agricultural cultivation (Uddin et al., 2014).

The objectives of this study are to determine and describe the socio-economic characteristics of farmer, to study the factors contributing to the adoption of disaster risk reduction strategies in agriculture and to identify the constraints of farmer access to disaster risk reduction strategies in agriculture.

\section{MATERIALS AND METHODS}

\section{About the study area}

This study was conducted in selected three villages- Bogi, Khuriakhali, and Chaltabunia under Southkhali union of Sarankhola upazila in Bagerhat district. The upazila is situated in the Southwest part of Bangladesh and is located between $22^{\circ}$ $13^{\prime}$ and $22^{\circ} 24^{\prime}$ North latitudes and between $89^{\circ} 46^{\prime}$ and $89^{\circ} 54^{\prime}$ East longitudes on the western part of the lower Meghna River with an altitude of $3.0-3.5 \mathrm{~m}$ from Mean Sea Level (MSL). The reasons behind the selection of this area were: the upazila has a high level of agricultural activities and most are vulnerable villages due to their geographical location (Figure 1).

\section{Population and sampling}

All farmers in the selected three villages constitute the population of the study. At first a list of all the farmers in the selected villages was prepared. In total 356 farmers were found whose are directly associated with agricultural practices. Thirty percent of the populations were randomly selected as the sample of the study; here the sample size of the study was 120 (Rashid and Islam, 2016).

\section{Data collecting instrument}

A structured interview schedule was used as the data-gathering instrument. The interview schedule was carefully prepared considering the objectives of the study. Qualitative method such as Key informant interviews and focus group discussion was implied to get a clear picture of this situation.

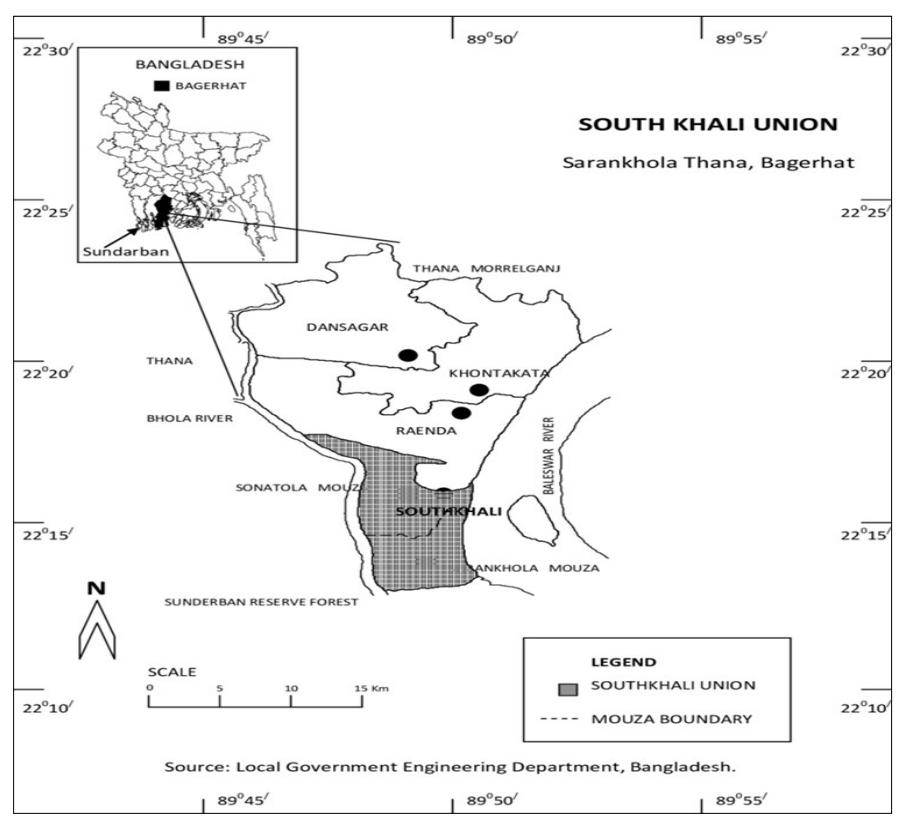

Figure 1. Map of Sharankhola Upazila showing study area. 


\section{Statistical tests}

Firstly the data were inputted in a master sheet which obtained from the respondents then compiled, tabulated and analyzed in accordance with the objectives of the study. Range, mean, percentage distribution and standard deviation those statistical methods were used in describing the dependent and independent variables. Tables were used to presenting the data. Pearson's Product Moment Coefficients of correlation ( $r$ ) analysis was used for exploring the relationship between the selected characteristics of the farmers with their access to Disaster risk reduction strategies. Regression analysis helps to understand how the typical value of the dependent variable (or 'criterion variable') changes when any one of the independent variables is varied, while the other independent variables are held fixed. Most commonly, regression analysis estimates the conditional expectation of the dependent variable given the independent variables that is, the average value of the dependent variable when the independent variables are fixed.

\section{RESULTS AND DISCUSSION}

\section{Socio-economic characteristics of the Farmers}

In the study, nine characteristics of farmers were selected for investigation. These characteristics were age, educational qualification, family member, farming experience, annual income, training exposure, farm size, source of information and organizational support (Table 1) (Jhahan et al., 2017).
Through this study tried to find out the rate of adopting disaster risk reduction strategy in agriculture as a result of change in climate, identifying the socio-economic factors which associated with adoption of coping strategies. Majority (83.2\%) of the respondents was found middle to young aged, who is more aware about climate change impact and different adaptation method to cope with situation rather than old one. Acquah (2011) found that the adaptation to climate change effect in agriculture sector is more adopted by middle to young aged farmers then old aged. Uddin et al. (2014) found that age is negatively related with adaptive strategies to climate change effects. On the other hand most (76.7\%) of the respondents are primary to secondary level educated that play a very important role in adoption of risk reduction strategy in agriculture. Quayum and Ali (2012) found that if the farmers are become educated then their adoption level for climate resilient coping strategies in agriculture sector will be increased accordingly and also explored that the educational level of farmers were positively related with the awareness on farming environment. Alongside the huge (98.3\%) respondents of this area had medium to low annual income, which fall pressure on farmer to adopt such coping strategy in agriculture. Deressa et al. (2009a, b) found that the farmers who have higher-income are more interested to adopt agricultural innovations against any disaster. Kim et al. (2012) found that household income positively influences the adoption of adaptive measures to climate change on their farm land, while Gbetibouo (2009) explained that wealthier

Table 1. Information about socio-economic characteristics of farmers.

\begin{tabular}{|c|c|c|c|c|}
\hline Characteristics & Category & Percentage & Mean & Std. Dev. \\
\hline \multirow[t]{3}{*}{ Age } & Category-1 (23-39 years) & 25.8 & 45.80 & 9.79 \\
\hline & Category-2 (40-55years) & 57.4 & & \\
\hline & Category- 3 (>55 years) & 16.8 & & \\
\hline \multirow[t]{3}{*}{ Family size } & Small family (up to 6 persons) & 71.7 & 5.61 & 1.68 \\
\hline & Medium family (7-9 persons) & 26.6 & & \\
\hline & Large family (>9 persons) & 1.7 & & \\
\hline \multirow[t]{5}{*}{ Education } & Illiterate & 4.2 & 5.44 & 3.46 \\
\hline & Only sign & 16.7 & & \\
\hline & Primary ( $1-5$ class) & 34.2 & & \\
\hline & Secondary (6-10 class) & 42.5 & & \\
\hline & Higher secondary(11-12 class) & 2.5 & & \\
\hline \multirow{3}{*}{ Annual income } & Low income (up to 67) & 78.3 & 58.11 & 18.4 \\
\hline & Medium income (68-109) & 20 & & \\
\hline & High income (above>109) & 1.6 & & \\
\hline \multirow[t]{3}{*}{ Farming experience } & Short term (up to 19 years) & 53.3 & 18.88 & 9.32 \\
\hline & Medium term (20-35 years) & 45 & & \\
\hline & Long term(above 35 years) & 1.6 & & \\
\hline \multirow[t]{3}{*}{ Training experience } & Low training (0-20days) & 32.50 & 25.82 & 17.3 \\
\hline & Medium training (21-40days) & 49.20 & & \\
\hline & High training (above 40days) & 18.30 & & \\
\hline \multirow[t]{3}{*}{ Farm size } & Small size (up to 2 ) & 65.8 & 2.06 & 1.36 \\
\hline & Medium size (3-5) & 25.0 & & \\
\hline & Large size (above>5) & 9.2 & & \\
\hline \multirow[t]{3}{*}{ Communication exposure } & Low CE (up to 12) & 30.0 & 14.56 & 4.18 \\
\hline & Medium CE (13-20) & 62.5 & & \\
\hline & High CE (above 20) & 7.5 & & \\
\hline \multirow[t]{3}{*}{ Organizational support } & Less support (up to 9) & 15.8 & 12.68 & 2.86 \\
\hline & Moderate support (10-14) & 61.7 & & \\
\hline & High support (above>14) & 22.5 & & \\
\hline
\end{tabular}


farmers are more interested to adapt by changing planting practices, using irrigation, and altering the amount of land farmed. Further, Nhemachena and Hassan (2007), indicate that farmers' decisions to take adaptation measures are highly dependent on their per capita income. But as the family size of maximum (98.3\%) respondents has small to medium and most (65.8\%) of the farmer had small farm size that help them to invest more in adopting such coping strategy in their cultivated land, rather than other sector. According to Mignouna et al. (2011), adaptation strategies to climate change effects will be adopted frequently if the farmers are belonging from a small family. That means the family size has a great influence on probability of adopting the adaptive strategy in agricultural sector. The farmer hold a perception that small sized family has positive role, where they can invest more in education and training for their own skill development which can helps in rising awareness about climate and adopting more disaster risk reduction strategies in agriculture sector. Acquah (2011) explored that the adoption of climate resilient agricultural practice will be increased with the decrease of farm size, because larger farms require inputs such as seeds, fertilizer, pesticides, irrigation facilities, and more at rates which are stressors on farm budgets. On the other hand, Sutradhar (2002) found that if the farmer had large farm for cultivation then they were more aware about environmental degradation. Majority (98.3\%) of the respondents has short to medium term farming experience. Because most of the farmer of this area is middle to young aged and it is hoped that with the increase of age and farming experience, the level of adopting disaster risk reduction strategy will be enhanced frequently. Accordingly Rokonuzzaman et al. (2006), the farmers' who have long term farming experience, they are more practicing different sustainable agriculture strategy in their cultivable land. Maximum (81.7\%) respondents of this area had medium to low training experience because recently the farmer starting to take training on climate change adaptation in agriculture for frequent climate change attack in this area. Uddin et al. (2014), revealed that the probability of adopting adaptive strategy is higher for those farmers who have connections with different training program compared to farmers not participating in such program and activity. Most (92.5\%) of the responds had medium to low communication exposure towards adoption of disaster risk reduction strategy in agriculture sector. And the most frequent use of communication media is mobile phone in this area, which helps farmer to remain alert about the climatic condition and getting valuable information about agricultural production and climate change adaptation. Farhad (2003) showed that the source of information of the farmers had a significant positive relationship with their adoption of climate resilient agricultural practices. Maximum (84.2\%) respondents of this area got medium to high organizational support from different GO and NGO. Uddin et al. (2014), showed that different kind of Government Organizations (GOs) and NonGovernment Organizations (NGOs) projects were designed to innovate some alternative livelihoods opportunities for farmer so that they can diversify and supplement their income and keep their agricultural operations on running position in the face of climatic uncertainty. Hamid (1997) observed that the less progressive farmers are taking more external support to get rid of worst situation then a progressive one. As the study area is rural based area and external supporting level is moderate to high so that it is a positive sign for this area's farmer to improving in agricultural sector for climate change adaptation and disaster risk reduction.

\section{Effect of climate change}

Bangladesh has a large agrarian base with 76 per cent of the total population living in the rural areas and 90 per cent of the rural population directly related with agriculture (Mohajan, 2014). The agricultural sector, comprising 48.10 per cent of the country's labour force (Golder et al., 2013) is already under pressure because of increase in the demand of foods and problems associated with the depletion of agricultural land and water resources. The issues of climate change make the pressure more acute. In this research was specified some climate change effect criteria to know the last few years change in Sarankhola upazila due to climatic effect (Table 2).

Table 2. Rate of climate change effect.

\begin{tabular}{|c|c|c|c|c|c|c|c|}
\hline \multirow{2}{*}{ Statement } & \multicolumn{5}{|c|}{ Category } & \multirow{2}{*}{ WM* $^{*}$} & \multirow{2}{*}{ Rank } \\
\hline & Very severe & Severe & Moderate & Low & Very low & & \\
\hline Temperature change & 37 & 35 & 40 & 8 & 0 & 3.85 & 4 \\
\hline Sea level rise & 44 & 54 & 13 & 9 & 0 & 4.11 & 2 \\
\hline Rainfall change & 28 & 48 & 41 & 13 & 0 & 3.84 & 5 \\
\hline Flood & 36 & 20 & 54 & 10 & 0 & 3.68 & 6 \\
\hline Cyclone & 31 & 68 & 419 & 2 & 0 & 4.07 & 3 \\
\hline Water logging & 15 & 13 & 75 & 12 & 5 & 3.18 & 7 \\
\hline Drought & 0 & 1 & 47 & 41 & 31 & 2.16 & 10 \\
\hline Land use change & 17 & 26 & 48 & 17 & 12 & 3.16 & 8 \\
\hline Hailstorm & 0 & 8 & 9 & 29 & 74 & 1.6 & 11 \\
\hline Salinity & 47 & 43 & 30 & 0 & 0 & 4.14 & 1 \\
\hline River bank erosion & 10 & 12 & 67 & 20 & 11 & 2.92 & 9 \\
\hline
\end{tabular}

Note: ${ }^{*} W M($ Weighted Mean $)=($ Very severe $\times 5+$ severe $\times 4+$ moderate $\times 3+$ low $\times 2+$ very low $\times 1) \div 120$ (Source: Field study) (Rashid and Islam, 2016). 
The above mentioned Table 2 represent that the salinity and sea level rise are the major effect of climate change in Sharonkhola. Agricultural lowlands and deltas in Bangladesh could be flooded if the sea level rise become reached in $88 \mathrm{~cm}$ height (Miller, 2004). NAPA (National Adaptation Programme of Action of Bangladesh) has warned that the impact of saline water ingression is likely to be accelerated by sea level rise, land subsidence and low flow river condition in estuary and underground water (NAPA, 2005). Sea level rise affects agriculture in three ways, i.e., by salinity intrusion, by flooding and by increasing cyclone frequency and its depth of damage (Hossain and Noor, 2016). The accumulative effects of those factors reduce quantity and quality of agricultural production in the coastal zone. In hot and dry season the salinity problem is more acute than wet season (Baten et al., 2015). Due to salinity and sea level rise the agriculture productive farmers are face great challenge, it also fall effect on human health and food security that really a major problematic situation for this area. These all effects are inter linked to each other like- if there was increasing temperature it may occur liquefying of glacier that in consequence raising the level of sea and exacerbated salinity intrusion. On the other hand temperature change also induces change in rainfall like- heavy rainfall that may occur cyclone, flood, river bank erosion etc. and erratic rainfall that may occur drought. So it can be said that if there was changed in any one climatic factor it will be changed the overall climate of environment. According to field survey analysis it was found that impact scores on climate change of the respondents ranged from 33 to 52 with an average being 41.63 and the standard deviation 4.87. On the basis of difference among observed maximum and minimum impact score and then divided by 3 for creating three section of group who have low, medium and high impact. The following categories were formulated in the Table 3.

Results furnished in Table 3 shows that highest proportion (39.2\%) of the respondents were in medium impact category compared to 37.5 percent in low and only 23.3 percent in high impact. Because most of the farmers are middle aged, secondary level educated and the existing farmers are more aware about climate change then old aged farmer. On the other hand the farmers are also getting training on agriculture and other related support from different GOs and NGOs, so it is an advantage for the farmer to adopt new practices in agricultural field to cope with the risk of disaster. According to Kamruzzaman (2015), found that most of the farmers (69.3\%) felt that between last 5 to15 years the climate change impact become more dangerous than past era and half of the farmers (48.0\%) believed that climate is frequently changing due to environmental factor rather than supernatural factor.

\section{Agricultural impact}

During SIDR and AILA cyclone the devastation was havoc in agricultural sector, especially in Sharankhola area (Mohosin, 2012). Due to salinity problem farmers have been facing a lot of constraint to bring all of their arable land under crops cultivation, especially, during winter Boro crops season almost $53 \%$ of their land remain untilled (Haque, 2006), and the other reasons are: non-availability of quality seeds, agricultural equipment's, timely low interest or interest free loan. The major damage in agricultural sector due to climate change are-less productivity, flooded land, soil erosion, soil salinity, pest attack, cultivable land damage, fertility decrease (Table 4).

Table 3. Distribution of the respondents according to their level of impact.

\begin{tabular}{lccc}
\hline \multirow{2}{*}{ Categories } & \multicolumn{2}{c}{ Respondents } & \multirow{2}{*}{ Mean } \\
\cline { 2 - 3 } & Number & Percent & \\
Low impact (up to 39) & 45 & 37.5 & \\
Medium impact (40-46) & 47 & 39.2 & \multirow{2}{*}{41.63} \\
High impact (above 46) & 28 & 23.3 & 4.87 \\
Total & 120 & 100 & \\
\hline
\end{tabular}

(SD: Standard Deviation, Source: Field survey).

Table 4. Rate of agricultural impact.

\begin{tabular}{|c|c|c|c|c|c|c|c|}
\hline \multirow{2}{*}{ Statement } & \multicolumn{5}{|c|}{ Category } & \multirow{2}{*}{ WM$^{*}$} & \multirow{2}{*}{ Rank } \\
\hline & Very severe & Severe & Moderate & Low & Very low & & \\
\hline Decline productivity & 21 & 34 & 63 & 2 & 0 & 3.62 & 3 \\
\hline Damage of cultivable land & 32 & 38 & 12 & 38 & 0 & 3.53 & 4 \\
\hline Soil salinity & 57 & 50 & 4 & 9 & 0 & 4.29 & 1 \\
\hline Pest attack & 45 & 45 & 20 & 10 & 0 & 4.04 & 2 \\
\hline Soil fertility decrease & 11 & 43 & 59 & 7 & 0 & 3.48 & 6 \\
\hline Soil erosion & 10 & 21 & 60 & 24 & 5 & 3.06 & 7 \\
\hline Flooded land & 15 & 48 & 47 & 10 & 0 & 3.49 & 5 \\
\hline
\end{tabular}

Note: ${ }^{*} \mathrm{WM}$ (Weighted Mean) $=($ Very severe $\mathrm{x} 5+$ severe $\mathrm{x} 4+$ moderate $\mathrm{x} 3+$ low $\mathrm{x} 2+$ very low $\mathrm{x} 1) \div 120$ (Source: Field study) (Rashid and Islam, 2016).

Table 5. Distribution of the respondents according to their impact level.

\begin{tabular}{lccc}
\hline Categories & \multicolumn{2}{c}{ Respondents } & Mean \\
\cline { 2 - 3 } & Number & Percent & SD \\
\hline Low impact (up to 24) & 23 & 22.5 & \\
Medium impact (25-31) & 63 & 47.5 & 26.78 \\
High impact (above 31) & 34 & 30 & 4.00 \\
Total & 120 & 100 & \\
\hline
\end{tabular}

(SD: Standard Deviation, Source: Field survey). 
This Table 4 showed that the major effect of climate change in agriculture is increase soil salinity and pest attack which indirectly decrease food production level and create food crisis in affected area. About 830,000 million hectares of land at coastal Bangladesh were affected by soil salinity at different degrees (Baten et al., 2015). Due to $0.3 \mathrm{~m}$ sea level rise in coastal area of Bangladesh there have a net reduction of 0.5 million MT of rice production each year (Islam, 2004). The rate of salinity intrusion in coastal Bangladesh is faster than it was predicted a decade ago (Agrawala et al., 2003). Even though salinity intrusion is a slow process, but the impact is devastating which will eventually contribute to loss of agricultural production and thus threat food security (Sarwar, 2005). In Bangladesh, coastal area constitutes $20 \%$ of the country of which about $53 \%$ are affected by different degrees of salinity (Haque, 2006).

Agricultural impact alert farmer about their damage and loss and what techniques should be taken for faster recovery and longer sustainability towards disaster risk. Agricultural impacts scores due to disaster risk ranged from 18 to 35 with an average being 26.78 and the standard deviation 4.00. On the basis of deviation between observed maximum and minimum agricultural impacts score and then fraction in three categories by dividing the deviation score by 3 , than the following categories were formulated in the Table 5.

Results furnished in Table 5 shows that highest proportion (47.5\%) of the respondents were in medium impact category compared to $30 \%$ in high and only $22.5 \%$ in low impact. According to Mohosin (2012), the Sharankhola is one the worst affected upazilas due to situated near coastline, where salinity is a current problem, which is expected to exacerbate by sea-level rise that affect food grain production and create food scarcity in Sharankhola upzila.
Adoption of disaster risk reduction strategy in agriculture The adopting of adaptation measures refers to an adjustment in natural or human systems in response to actual or expected climatic conditions (Kurukulasuriya and Mendelsohn, 2008). Community-based adoption can greatly benefit from knowledge of local coping strategies. Baumwoll (2008), showed that, in recent years, shift in the approach to DRR can be found with and introduction of the vulnerability approach, a focus on predisaster activities and an inclusion of the affected community. Through this study tried to develop a local coping strategies database to facilitate the transfer of long-standing coping strategies and knowledge from communities which was adapted to specific hazards or climatic conditions by the community. Empirical evidence suggests that the most common farm-level adaptation strategies to climate change are changing crop varieties, irrigation, planting trees, crop and livestock diversification, soil conservation, early and late planting, increasing plant spacing, using clay soil, and adjusting the level and timing of fertilizer application (Kurukulasuriya and Mendelsohn, 2008; Molua, 2009; Nhemachena and Hassan, 2007). Practicing soil and water conservation techniques (Asfaw and Lipper, 2011), fertilizer use, irrigation (Mortimore and Adams, 2001 and Morton, 2007) and diversification to non-farm activities (Howden et al., 2007 and Eakin, 2005) are also adaptation strategies that have been practiced at farm level in response to climate change. The farmers of Sharankhola are changing their cropping patterns due to climate change especially after SIDR and AILA. Increase in salinity intrusion and increase in soil salinity will have serious negative impacts on agriculture so that farmer of this area harvesting rain water and planting more tree for reducing soil salinity and increasing soil humidity. Most farmers follow cropping patterns that involve sequential cropping, mixedcropping, and relay cropping, Sarjon method. The specific adoption and its using percentage are given below in Figure 2.

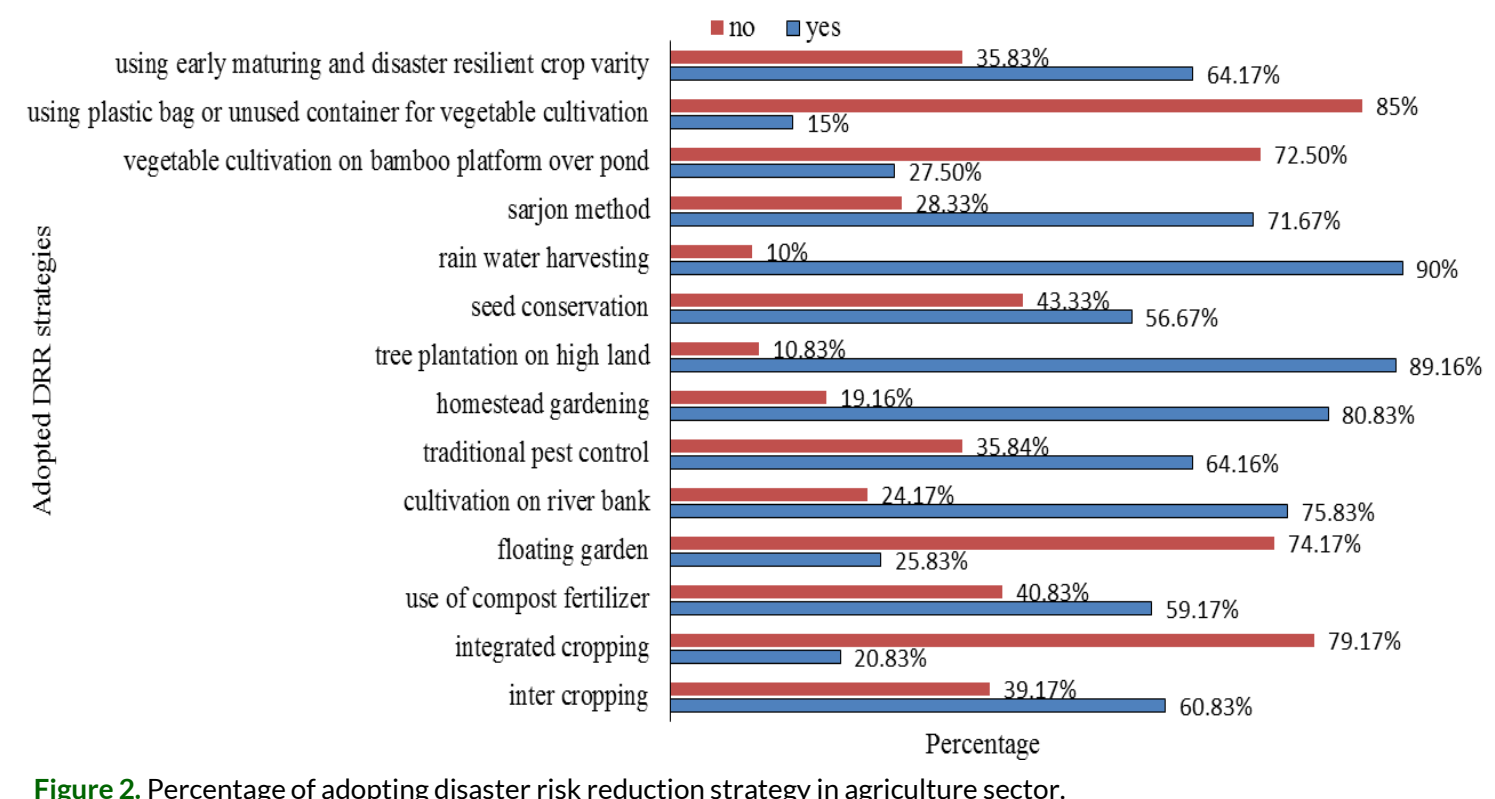

Figure 2. Percentage of adopting disaster risk reduction strategy in agriculture sector. 
Table 6. Distribution of the respondents according to their adoption level.

\begin{tabular}{lccc}
\hline \multirow{2}{*}{ Categories } & \multicolumn{2}{c}{ Respondents } & \multirow{2}{*}{ Mean } \\
\cline { 2 - 3 } & Number & Percent & \multirow{2}{*}{ SD } \\
\hline Low adoption (up to 73) & 51 & 42.5 & \\
Medium adoption (74-128) & 63 & 50.8 & \multirow{2}{*}{79.78} \\
High adoption (above 128) & 6 & 6.7 & \multirow{2}{*}{31.04} \\
Total & 120 & 100 & \\
\hline
\end{tabular}

(SD: Standard Deviation.) (Source: Field survey).

Table 7. Relationship between selected characteristics of the respondents and their adaptation of disaster risk reduction strategies towards agriculture sector.

\begin{tabular}{|c|c|c|}
\hline Dependent variable & Independent variables & $\begin{array}{l}\text { Co-efficient of } \\
\text { correlation }(r)\end{array}$ \\
\hline \multirow{5}{*}{ Adoption of disaster risk reduction strategies towards agriculture sector } & Age & $0.383^{* *}$ \\
\hline & Farming experience & $0.441^{* *}$ \\
\hline & Communication exposure & $0.271^{*}$ \\
\hline & Organizational support & $0.226^{*}$ \\
\hline & Climate change effect & $-0.266^{* *}$ \\
\hline
\end{tabular}

* Significant at 0.05 level of probability, ${ }^{* *}$ Significant at 0.01 level of probability.

Table 8. Regression coefficients between adopted strategies of the respondents with their selected characteristics.

\begin{tabular}{lccccc}
\hline Predictor Variable & B & SE & $\boldsymbol{\beta}$ & P & VIF \\
\hline Age & 0.372 & 0.339 & 0.118 & 0.274 & 2.406 \\
Farming experience & 1.816 & 0.363 & 0.546 & 0.000 & 2.502 \\
Communication exposure & 2.706 & 0.613 & 0.364 & 0.000 & 1.5438 \\
Organizational support & 1.783 & 0.989 & 0.165 & 0.074 & 1.753 \\
Climate change effect & -0.887 & 0.523 & -0.139 & 0.093 & 1.421 \\
$\mathrm{R}^{2}=0.459$ & Adj. $=0.435$ & & $\mathrm{~F}=19.31$ & $\mathrm{P}<0.000$ \\
\hline
\end{tabular}

The Figure 2 shown that rain water harvesting (90\%) because of salinity intrusion in farm land area and tree plantation on high land (89.16\%) for protecting crop from sudden disaster risk are the most adopted risk reduction strategy in Sharonkhola upazila. Irrigation increases the yield of production (Paul et al., 2013 and Tolga et al., 2006), improving nutrient availability to the plants (Aza-Gnandji et al., 2013 and El-Ashry et al., 1985). Uddin et al. (2014), was ranked irrigation as the first among farm adaptation strategies, while crop insurance has ranked as least important. Currently, farmers of Sharankhola (study area) can apply two main coping mechanisms to counter these developments: digging canals (khals) for freshwater reservation and cultivating saline-resistant crops (Mohosin, 2012). Homestead gardening (80.83\%) is the second most adopted practice of this area, which is one of the most disaster resilient and climate change adapted technology in agriculture sector. On the other hand vegetable cultivation on bamboo platform over pond (27.5\%), floating garden (25.83\%), integrated cropping (20.83\%) and using of plastic bag or pot for cultivation (15\%) are less adopted strategy in this area. Adoption of disaster risk reduction strategies in agriculture increase ones resiliency and coping capacity in agriculture sector. Adoption of those strategies makes farmer more sustainable towards disaster risk. Adaptation scores on disaster risk reduction strategies of the respondents ranged from 19 to 180 with an average being 79.78 and the standard deviation 31.04. On the basis of calculation like the deviation between observed maximum and minimum adaptation of disaster risk reduction strategies score and divided by 3 for classifying into three categories, the following categories were formulated in the Table 6.
Results furnished in Table 6 observed that an overwhelming majority (93.3\%) of the respondents in the study area had low to medium adoption of disaster risk reduction strategies in agriculture because major portion of farmer in this area is middle aged and in recent time the farmer starting to practice such new risk reduction strategies in agriculture due to frequent climate change effect on agriculture.

Relationship between selected characteristics of the respondents and adoption of disaster risk reduction practices in agriculture sector

Pearson Product Moment co-efficient was computed in order to find out the extent of relationship between the dependent variable and independent variables (at $1 \%$ and $5 \%$ level of significance). The results of correlation analysis are shown in Table 7.

Farmer's age and adoption of disaster risk reduction strategies in agriculture

The co-efficient of correlation between age and their adopted strategies in agriculture towards DRR was found positive and significant at $1 \%$ level of probability $\left(r=0.383^{* *}\right)$. This indicates that adoption of disaster risk reduction strategies in agriculture increase with their increasing age.

Farming experience and adoption of disaster risk reduction strategies in agriculture

The co-efficient of correlation between farming experience and their adopted coping strategies towards agriculture was found positive and significant at $1 \%$ level of probability $\left(r=0.441^{* *}\right)$. 
This indicates that adoption of disaster risk reduction strategies in agriculture will be increased with their increasing farming experience in agriculture.

Communication exposure and adoption of disaster risk reduction strategies in agriculture

The co-efficient of correlation between communication exposure and adopted coping strategies towards agriculture was found positive and significant at 5\% level of probability $(r=$ $0.271^{*}$ ). This indicates that adoption of disaster risk reduction strategies in agriculture will increase with their increasing availability of communication system.

Organizational support and adoption of disaster risk reduction strategies in agriculture

The co-efficient of correlation between external support and adopted strategies towards agriculture was found positive and significant at $5 \%$ level of probability $\left(r=0.226^{*}\right)$. Also the findings indicate that more organizational support of the respondents lead to a tendency towards more adoption of disaster resilient practices in agriculture for reducing risk and increasing sustainability.

Climate change effect and adoption of disaster risk reduction strategies in agriculture

The co-efficient of correlation between climate change effect and adopted strategies towards agriculture was found negative and significant at $1 \%$ level of probability $\left(r=-0.266^{* *}\right)$. The findings indicate that adoption of disaster risk reduction strategies in agriculture will increase with their decreasing climate change effect on agriculture.

Results furnished in Table 8 shows that the $R^{2}$ value is 0.459 and corresponding $F$ value is 19.31 which were significant at 0.001 levels. The $R^{2}$ value indicating that 45.9 percent of the total variation in adoption of disaster risk reduction strategies in agriculture was explained by five variables included in the regression analysis. The results show that the adoption of disaster risk reduction strategies in agriculture is the function of age $(\beta=0.118)$, farming experience $(\beta=0.546)$, communication exposure $(\beta=0.364)$, organizational support $(\beta=0.165)$ and climate change effect $(\beta=-0.139)$. The farming experience $(\beta=0.546)$ has the strongest contribution to the adoption of disaster risk reduction strategies in agriculture. It is therefore, concluded that if we increase farming experience 1 unit, the adoption of disaster risk reduction strategies in agriculture by the respondents will be 1.546. The results also indicated that climate change effect ( $\beta=-0.139$ ) had negative contribution to the adoption of disaster risk reduction strategies in agriculture. The adoption of disaster risk reduction strategies in agriculture will be 1.139 when the climate change effect decreases 1 unit.

Regression coefficients between adopting disaster risk reduction practices of the respondents with their selected characteristics

For predicting the contribution of the factors in adopting strategies of the respondent in agriculture the regression method was applied. Among the eleven characteristics, six characteristics were selected for regression analysis which had shown significance relationship with the adopted strategies (dependent variable) in correlation coefficients. Age, farming experience, communication exposure, external support and climate change effect in agriculture were selected for regression analysis. Regression coefficients of adopted strategies of the respondents with their selected characteristics are shown in the Table 8.

Constraints of adopting disaster risk reduction strategies towards agriculture faced by the respondents

The farmers of this area are using different coping strategy in agriculture sector for adapting with current climate change conditions, but they are still facing more or less problem in the application of those strategies. Constraints faced by the farmers in respect of, adopting disaster risk reduction strategies in agriculture sector were constructed in Figure 3.

Constraints furnished in Figure 3 indicate that, the most serious constraints are lack of economic facility and lack of infrastructure. Whereas this area is saline affected area, so that without economic development the farmers can't construct infrastructure to preserve water for irrigation and also infrastructure likeembankment etc. that needs for controlling flood water. According to Mohosin (2012), several barriers have been identified to effective adaptation of disaster risk reduction strategy in agriculture sector including the lack of: freshwater, quality seeds, capacity building, and training for farmers and the impact of climate change on agriculture is factual truth and it will be worsen if governments and donors fail to take suitable steps right now. As we know Bangladesh is an agrarian country so that its urgently needs to develop climate resilient agriculture cultivation pattern for its people to survive and prosper in the long term.

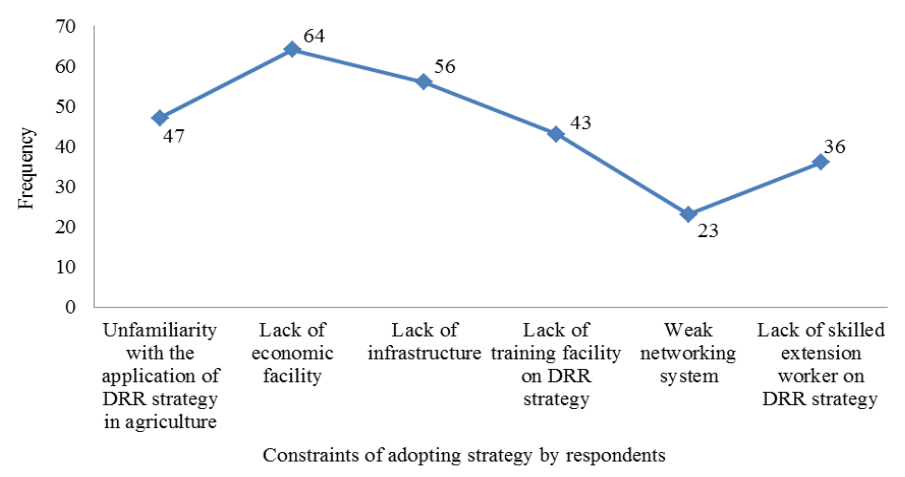

Figure 3. Constrains of adopting disaster risk reduction strategies in agriculture. 


\section{Conclusion}

This study established the adoption level of disaster risk reduction strategy in crop agriculture sector by farmer of Sharankhola upazila. The farmers in this area were generally poor and have marginal income. On the other side this area is most climate change generated disaster affected area due to its geo graphical location. The most horrible climate change effect in this area is salinity, sea level rise and cyclone which all are equally responsible for destruction in agricultural sector especially raising soil salinity and pest attack. Although for handling this situation the farmer of this area may take some own initiatives like- adoption of some local coping strategy for primary level protection in agriculture sector with the help of some govt. and non govt. organizations but there are still existing some constraints that hampered the rate of adopting such strategies to reach in up to the mark. This study represents a preliminary venture about adoption rate of disaster risk reduction strategy in agriculture by the farmer and showing that the socioeconomic characteristics of farmer had a great influence in adopting such strategy in agriculture. According to the study it is found that farming experience is the strongest contributing factor of adopting DRR strategy in agriculture sector and the adoption level will be developed with increasing of farmer's age, effective communication system, organizational support and decreasing of climate change impacts. But to coordinated all this factor the Govt. of Bangladesh and different GO and NGO has play a very great role, so that they should come forward to take some steps towards providing proper training program, proper supporting system and proper application method of those risk reduction strategies in agriculture sector to climate change adaptation because all are possible if the farmers of Bangladesh are more aware about climate change effect and more skilled about applying coping strategy in effective manner and in proper way.

\section{ACKNOWLEDGEMENTS}

The authors thank the authority of Patuakhali Science and Technology University (PSTU) and Ministry of Science and Technology (MoST) for providing support and financial facility as a NST student fellowship to complete this study.

Open Access: This is an open access article distributed under the terms of the Creative Commons Attribution 4.0 License, which permits unrestricted use, distribution, and reproduction in any medium, provided the original author(s) if the sources are credited.

\section{REFERENCES}

Acquah, H.D. (2011). Farmers'perception and adaptation to climate change effects: A willingness to pay. Journal of Sustainable Development Africa, 13(5): 150161.

ADPC, (2008). Draft Disaster Management Information Link Report, Comprehensive Disaster Management Programme (CDMP), Component 5b, Ministry of Food and Disaster Management (MoFDM), Government of Peoples" Repub- lic of Bangladesh, Dhaka, Bangladesh. https://www.preventionweb.net/ files/22229_22229dminseriesreport1dminfolinkrep.pdf

Agrawala, S., Ota, T., Ahmed, A.U., Smith, J. and Aalst, M.V. (2003). Development and climate change in Bangladesh: Focus on coastal flooding and the Sunderbans. Organization for Economic Co-Operation and Development (OECD), http://www.oecd.org/dataoecd/46/55/21055658.pdf

Alauddin, M. and Rahman, S. (2013). Vulnerability to climate change and adaptation practices in Bangladesh. Journal of SUB, 4(2): 25-42.

Asfaw, S. and Lipper, L. (2011). Economics of PGRFA Management for Adaptation to Climate Change: A Review of Selected Literature; Background Study Paper No. 60; Agricultural Economic Division: Rome, Italy, www.fao.org/docrep/meeting/023/mb695e.pdf

Aza-Gnandji, Ruben, C.D., Xu, Raitt, Y., Levy, L. and Jonathan (2013). Salinity of irrigation water in the Philippi farming area of the Cape Flats, Cape Town, South Africa. Journal of Earth Science, 39: 199-210, http://hdl.handle.net/10566/709

Baten, M.A., Seal, L. and Kazi, S.L. (2015). Salinity intrusion in interior coast of Bangladesh: Challenges to agriculture in south-central coastal zone. American Journal of Climate Change, 4(3): 248-262, https:// www.researchgate.net/.../279232138_Salinity_Intrusion_in_Interior_Coast_ of_Bangladesh

Baumwoll, J. (2008). The Value of Indigenous Knowledge for Disaster Risk Reduction: A Unique Assessment Tool for Reducing Community Vulnerability to Natural Disasters, Bangkok, UN/ISDR, https://books.google.com.bd/books?id=Upi6PgAACAAJ

BBS (2011). Population Census. Bangladesh Bureau of Statistics, Dhaka.

BBS (2018). Population Census 2012 National Report (Provisional). Bangladesh Bureau of Statistics, Barisal.

CCC (Climate Change Cell) (2007). Climate Change and Bangladesh. Department of Environment, Government of the People's Republic of Bangladesh, Dhaka, http://www.bdresearch.org.bd/home/climate_knowledge/cd1/pdf/ Bangladesh\%20and\%20climate\%20change/Climate\%20change\%20impacts\% 20,vulnerability,\%20risk/Climate\%20Change\%20And\%20Bangladesh.pdf

Deressa, T.T., Hassan, R.M. and Ringler C. (2009a). Assessing household vulnerability to climate change: The case of farmer as in the Nile Basin of Ethiopia. Washington, DC., https:// www.researchgate.net/.../46442040_Assessing_household_vulnerability_to_ climate change

Deressa, T.T., Hassan, R.M., Ringler, C., Alemu, T. and Yesuf, M. (2009b). Determinants of farmers' choice of adaptation methods to climate change in the Nile Basin of Ethiopia. Journal of Global Environment Change, 19(2): 248-255, https://doi.org/10.1016/j.gloenvcha.2009.01.002

Eakin, H. (2005). Institutional change, climate risk, and rural vulnerability: Cases from central Mexico. Journal of World Development, 33(11): 1923-1938, https://doi.org/10.1016/j.worlddev.2005.06.005

El-Ashry, M.T., Schilfgaarde, J.V. and Schiffman, S. (1985). Salinity pollution from irrigated agriculture. Journal of Soil and Water Conservation, 40(1): 48-52, www.jswconline.org/content/40/1/48.full.pdf

Farhad, A.K.M. (2003). Knowledge Attitude and Practices of Rural Women in Using IPM Vegetable Cultivation, MS Thesis, Department of Agricultural Extension Education, Bangladesh Agricultural University, Mymensingh.

Gandure, S., Walker, S. and Botha, J.J. (2013). Farmers' perceptions of adaptation to climate change and water stress in a South African rural community. Journal of Environmental Development, 5: 39-53, https://doi.org/10.1016/j.envdev.2012.11.004

Gbetibouo, G.A. (2009). Understanding farmers' perceptions and adaptations to climate change and variability: The Case of the Limpopo Basin, South Africa. Washington, D.C.: International Food Policy Research Institute Discussion Paper 00849.

GOB (2008). Cyclone Sidr in Bangladesh: Damage, loss and needs assessment for disaster recovery and reconstruction. Retrieved from http://gfdrr.org/docs/Assessment

Golder, P.C., Sastry, R.K. and Srinivas, K. (2013). Research priorities in Bangladesh: Analysis of crop production trends. SAARC Journal of Agriculture, 11(1): 5370, https://doi.org/10.3329/sja.v11i1.18375

Haque, S.A. (2006). Salinity problem and crop production in coastal regions of Bangladesh, Department of Soil Science, Bangladesh Agricultural University, Mymensingh.

Hamid, M.A. (1997). Farmer's awareness on environmental pollution: A study in Bangladesh. Asia Pacific Journal of Rural Development, 6(2): 107-117. 
Haque, S.A. (2006). Salinity problem and crop production in coastal regions of Bangladesh. Journal on Botany, 38(5): 1359-1365, https://www.pakbs.org/pjbot/PDFs/38(5)/PJB38(5)1359.pdf

Hossain, B.M.S. and Noor M.A. (2016). Impact of climate change on agriculture and food security in Bangladesh. International Journal of Multidisciplinary Education and Research, 1(8): 05-11.

Nhemachena, R. and Hassan, R. (2007). Micro-level Analysis of Farmers Adaption to Climate Change in Southern Africa. Washington, DC: International Food Policy Research Institute Discussion Paper 000714.

Howden, S.M., Soussana, J., Tubiello, F.N., Chhetri, N., Dunlop, M. and Meinke, H. (2007). Adapting agriculture to climate change effects. Proceeding of Natural Academic Science USA, 104(50): 19691-19696, https://doi.org/10.1073/pnas.0701890104

Islam, M.R. (2004). Where Land Meets the Sea: A Profile of the Coastal Zone of Bangladesh. The University Press Limited, Dhaka.

Jhahan, I., Hasan, I. and Rahman, S. (2017). Awareness of Rural Women on Development Interventions to Livelihood Improvement: A Household level Analysis in Coastal Belt of Bangladesh. Journal of Sociology and Anthropology, 1(1): 33-40, http://www.sciepub.com/JSA/abstract/7774

Kamruzzaman, M. (2015). Farmers' Perceptions on Climate Change: A Step toward Climate Change Adaptation in Sylhet Hilly Region, PhD Thesis, Department of Agricultural Extension Education, Sylhet Agricultural University (SAU), Bangladesh.

Karim, M.F. and Mimura, N. (2008). Impacts of Climate Change and Sea-Level Rise on Cyclonic Storm Surge Floods in Bangladesh. Global Environmental Change, 18: 490-500, http://dx.doi.org/10.1016/j.gloenvcha.2008.05.002

Kim, C., Jung, H., Lee, S., Park, S. and Takei, A. (2012). An analysis on determinants of farmers' adaptation to climate change in Korea. Journal of Rural Development, $35 \quad$ (2): 53-72, https://ideas.repec.org/a/ags/jordng/174515.html

Kurukulasuriya, P. and Mendelsohn, R. (2008). A Ricardian analysis of the impact of climate change on African cropland. Africa Journal on Agricultural Resource Economy, 2(1): 1-23, https://ideas.repec.org/a/ags/afjare/56965.html

Mendelsohn, R. and Dinar, A. (1999). Climate change, agriculture, and developing countries: Does adaptation matter? The World Bank Research Observer, 14(2): 277-93, https://elibrary.worldbank.org/doi/abs/10.1093/wbro/14.2.277

Mignouna, D.B., Manyong, V.M., Rusike, J., Mutabazi, K.D.S. and Senkondo, E.M. (2011). Determinants of adopting imazapyr-resistant maize technologies and its impact on household income in Western Kenya. AgBioForum ISSN : 1522-936X, 14:158-163, http://agris.fao.org/agris-search/search.do? recordID=US201600076481

Miller, G.T. (2004). Living in the Environment. Brooks/Cole-Thomson Learning, Pacific Grove.

Mohajan, H.K. (2013). Food, Agriculture and Economic Situation of Bangladesh, Munich Personal RePEc Archive (MPRA) Paper No. 54240, posted 8. March 2014 14:42 UTC., http://mpra.ub.uni-muenchen.de/54240/

Mohosin, M.D. (2012). Impacts of Climate Change on Cropping Pattern in Coastal Region of Bangladesh: A Case Study of Sharankhola Upazila, Bagerhat, MS Thesis, BRAC University, Dhaka, Bangladesh.

MoP (2011). Sixth Five Year Plan of Bangladesh, General Economics Division, Planning Commission, Dhaka.

Molua, E.L. (2009). An empirical assessment of the impact of climate change on smallholder agriculture in Cameroon. Journal of Global Planet Change, 63(34): 205-208, https://doi.org/10.1016/j.gloplacha.2009.02.006

Morton, J.F. (2007). The impact of climate change on smallholder and subsistence agriculture. Proceedings of the National Academy of Sciences USA 104(50): 19680-19685, https://doi.org/10.1073/pnas.0701855104

Mortimore, M.J. and Adams, W.M. (2001). Farmer adaptation, change and "crisis" in the Sahel. Journal of Global Environmental Change, 11(1): 49-57,
https://doi.org/10.1016/S0959-3780(00)00044-3

NAPA (National Adaptation Programme of Action of Bangladesh) (2005). Ministry of Environment and Forest (MoEF), Government of the People's Republic of Bangladesh.

Park, S.E., Marshall, N.A., Jakku, E., Dowd, A.M., Howden, S.M., Mendham, E. and Fleming, A. (2012). Informing adaptation responses to climate change through theories of transformation. Journal of Global Environmental Change, 22(1): 115-126, https://doi.org/10.1016/j.gloenvcha.2011.10.003

Paul, J.C., Mishra, J.N., Pradhan, P.L. and Panigrahi, B. (2013). Effect of drip and surface irrigation on yield, water use- efficiency and economics of capsicum (Capsicum annum L.) grown under mulch and non-mulch conditions in eastern coastal India. Eurasian Journal of Sustainable Development, 2(1): 99108, http://dx.doi.org/10.14207/ejsd.2013.v2n1p99

Quayum, M.A. and Ali, A.M. (2012). Adoption and diffusion of power tiller in Bangladesh. Bangladesh Journal of Agriculture Research, 37(2): 307-325, https://doi.org/10.3329/bjar.v37i2.11234

Rashid, M. and Islam, R. (2016). Use of Communication Media by Fishing Community at Patharghata Upazila, MS Thesis, Department of Agricultural Extension and Rural Development, Patuakhali Science and Technology University, Patuakhali.

Rokonuzzaman, M., Hague, M., Alam, K.H., Ahsan, A. and Amin, M.A. (2006). Relationship between Twelve Selected Characters of Farmer and Perception of Sustainable in Matlab upazilla under Chandpur district. Journal of Socio Economic Research and Development, 3(1): 7-13, https://eurekamag.com/research/016/887/016887028.php

Sarwar, G.M., 2005: Impacts of Sea Level Rise on the Coastal Zone of Bangladesh. Unpublished Master's Thesis, Lund University, Lund.

Shaw, R., Mallick, F. and Islam, A. (2013). Climate Change: Global Perspectives. In: Shaw, R., Mallick, F., Islam, A. (Editors), Climate change adaptation actions in Bangladesh. Springer, Tokyo, pp. 3-14, https://www.springer.com/gp/book/9784431542483

Sikder, R. and Xiaoying, J. (2014).Climate change impact and agriculture of Bangladesh. Journal of Environment and Earth Science, 4(1): 2-14.

Sutradhar, N.C. (2002). Farmers Awareness on Environmental Degradation caused by the use of Modem Agricultural Technologies, MS Thesis, Department of Agricultural Extension Education. Bangladesh Agricultural University, Mymensingh.

Tasnim, N. (2012). Farmers' Awareness on Environment for Agriculture Farming Practices in Some Selected areas in Bogra District, PhD Thesis, Department of Environmental Science, Bangladesh Agricultural University, Mymensingh.

Tolga, E., Yesim, E., Halim, O. and Hakan, O. (2006). Water-yield relationships of potato under different irrigation methods and regimens. Science and Agriculture, 63(3): 226-231, http://dx.doi.org/10.1590/S0103-90162006000300003

Uddin, M.N., Bokelmann, W. and Scott, J.E. (2014). Factors affecting farmers' adaptation strategies to environmental degradation and climate change effects: A farm level study in Bangladesh, 2(4): 223-241, https://doi.org/10.3390/cli2040223

Wheeler, S., Zuo, A. and Bjornlund, H. (2013). Farmers' climate change beliefs and adaptation strategies for water scarce future in Australia. Journal of Global Environmental Change, 23(2): 537-547, https://doi.org/10.1016/j.gloenvcha.2012.11.008

World Bank (WB) (2013). Turn Down the Heat: Climate Extremes, Regional Impacts, and the Case for Resilience. A Report for the World Bank by the Potsdam Institute for Climate Impact Research and Climate Analytics. World Bank, Washington, D.C.

Yusuf, W.H., Alam, M., Hassan, A., Khan, A.S., Ruane, A.C., Rosenzweig, C., Major, D.C. and Thurlow, J. (2010). Climate Change Risk and Food Security in Bangladesh. Earth Scan, London. 